\title{
O Princípio da Proporcionalidade no Direito Ambiental: \\ Breves Exemplos de Implementação no Direito Brasileiro
}

\author{
Prenata Maciel Cuiabano
}

Procuradora do Estado de Mato Grosso, Mestranda no Programa de Pós-Graduação em Direito das Relações Sociais da Universidade Federal do Paraná (UFPR).

\section{SUMÁRIO}

Introdução;

Princípio da proporcionalidade e o Direito Penal Ambiental;

Considerações finais;

Referências bibliográficas.

\section{Introdução}

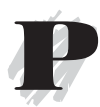

ode-se concordar com a afirmação do professor PAULO BONAVIDES, de que princípio da proporcionalidade faz parte daqueles princípios cujo teor se é mais fácil compreender do que explicar. ${ }^{1}$ Isto reflete também no processo de sua conceituação, já que também é conhecido como princípio da proibição do excesso ou princípio da razoabilidade.

$\bigcirc$ princípio da proporcionalidade remete à noção de coerência, cuja adequação depende dos valores escolhidos pelo sistema jurídico. A dinâmica da relação entre juiz e legislador é caracterizada pela constante tensão travada entre a aptidão do primeiro para empregar uma jurisprudência construtiva e as restrições impostas a esta atividade pela lei.

1 BONAVIDES, Paulo. Curso de direito constitucional. 4. ed. São Paulo: Ed. Malheiros, 1993, p. 315. 
Em regra, a coerência deve estar presente em todas as decisões jurídicas e políticas, inclusive no Direito Ambiental. É aqui que procuramos oferecer algumas reflexões, relacionando o princípio da proporcionalidade com o Direito do Ambiente, posicionando-o como instrumento de destaque na tarefa de enfrentamento da complexidade e especificidade de seus problemas.

Adotando a classificação de CANOTILHO, ${ }^{2}$ o princípio da proporcionalidade pode ser localizado no conjunto de princípios jurídicos fundamentais, caracterizados como "princípios historicamente objetivados e progressivamente introduzidos na consciência jurídica e que encontram uma recepção expressa ou implícita no texto constitucional". ${ }^{3}$

Os três elementos deste princípio são: a adequação, a necessidade e o princípio da proporcionalidade em sentido estrito (ou lei da ponderação), elaborados progressivamente durante o processo de criação das jurisprudências na Alemanha. ${ }^{4}$

Para analisar o princípio da proporcionalidade no direito ambiental neste curto espaço de tempo e de texto, organizamos o trabalho de modo a expor algumas hipóteses de sua aplicação no direito ambiental brasileiro.

Isto porque a efetividade da proteção do ambiente depende da aplicação do princípio da proporcionalidade, que no caso, lida com a difícil tarefa de harmonização e otimização de interesses e pretensões intensamente colidentes.

\section{Princípio da proporcionalidade e o Direito Penal Ambiental}

Pode-se dizer que no Direito Ambiental, a aplicação do princípio da proporcionalidade deriva do princípio da precaução. No princípio da precaução se encontra expressa a preocupação de se evitar a concretização de qualquer risco de perigo que possa ocasionar danos ambientais.

A aplicação da proporcionalidade ainda se justifica diante da natureza de algumas violações contra o meio ambiente, cujos efeitos são irreparáveis ou de difícil reparação, em nada se justificando a aplicação de uma pena grave.

A aplicação do princípio da proporcionalidade pode assim atuar como critério de verificação da arbitrariedade existente ou nas leis ambientais, ou no processo de sua aplicação.

Neste julgado, a desproporcionalidade incidiu no momento de aplicação da lei de fauna (Lei n⿳0 5.197/67), do seguinte modo:

"Penal. Crime contra a fauna. Abate de jacaré com finalidade alimen-

2 Na tipologia apresentada pelo professor JOSÉ JOAQUIM GOMES CANOTILHO, foi elaborada uma subdivisão dos princípios jurídicos em princípios fundamentais, princípios conformadores, princípios impositivos e princípios garantia. Direito constitucional. 5. ed. 2. reimpressão. Coimbra: Ed. Almedina, 1992, p. 1030-1040.

3 CANOTILHO, José Joaquim Gomes. Op. cit., p. 1038.

4 Para maiores esclarecimentos sobre o princípio da proporcionalidade e sua construção teórica, conferir STUMM, Raquel Denize. O princípio da proporcionalidade no direito constitucional brasileiro. 1. ed. Porto Alegre: Livraria do Advogado, 1995. 
tícia. Autoria Duvidosa. Ausência de atos de comércio. Conduta atípica. Caça sem finalidade predatória. Inexistência de dolo. Objetividade jurídica da Lei $\mathrm{n}^{\circ}$ 5.197/67. Proteção das espécies. Coibição de excessos comprometedores da fauna silvestre. Aplicação do princípio da insignificância. Desproporcionalidade da aplicação da pena à significação social do fato. Absolvição. Apelo provido.

I - $\mathrm{O}$ apelante foi condenado por ter participado da caça de um jacaré, que se destinava à sua alimentação e de seus amigos, não demonstrado de forma segura ter sido o autor do abate do animal, com finalidade de comércio.

II - A objetividade jurídica da Lei $n^{\circ}$ 5.197/67 é a tutela à fauna silvestre o equilíbrio ecológico e preservação das espécies, controlando e coibindo excessos seus rigores quando o caso concreto reclamar e justificar, a fim de que se cumpra sua finalidade e se alcance uma decisão justa, não se podendo falar que o simples abate esporádico de um animal que pertence à fauna silvestre, com a intenção de alimentar-se de sua carne, subsuma-se aos tipos que pune com severidade.

III - Aplicação do princípio da insignificância, visto que ínfima a afetação ao bem jurídico tutelado, não se justificando a apelação, ainda que mínima, por ser desproporcional à significação social do fato.

IV - Apelação a que se dá provimento, para absolver o apelante da prá- tica do delito previsto no art. $1^{\circ}$, combinado com o art. $27, \S 1^{\circ}$, ambos da Lei $\mathrm{n}^{\circ} 5.197 / 67$, com fulcro no art. 386, III do Código de Processo Penal". 5

O professor IVAN LIRA DE CARVALHO criticou a "aspereza" ínsita ao Código de Caça, colacionando interessante julgado relacionado à mitigação da interpretação do art. $1^{\text {o }}$ do Código de Caça (Lei n⿳0 5.197/67). Em sede de apelação criminal, ${ }^{6}$ foi feita a distinção entre ter e utilizar animal silvestre, para fins de enquadramento no art. $1^{\stackrel{o}{ }}$ da Lei de Caça e destacou que: "utilizar não é simplesmente ter. É mais que isso. É ter disso e tirar dele algum proveito, como, no caso de animal, usá-lo em exibição circense, servir-se dele para tracionar carroça, etc. Na hipótese subexamine, o recorrido apenas tinha os pássaros, mas não restou provado que os estava utilizando ou que já o tivesse feito, como igualmente não se comprovou qualquer ato de comércio a respeito".?

O professor da UFRN, através da indignação perante a irrazoabilidade de algumas leis ambientais, ressaltou a importância do papel do judiciário na moderação dos efeitos das leis ambientais punitivas. E afirma que "exemplo maior desse exagero punitivo está no art. 34 da lei em foco, com a redação ofertada pela Lei n⿳⺈ 7.653/88, estabelecendo que os crimes ali listados são inafiançáveis, num flagrante descompasso com a escala de valores norteadora do sistema penal brasileiro que, por exemplo, não

5 TRF - 3 $3^{\mathrm{a}}$ R. - AC 97.03.060410-2/SP - DJU 07.11.2000, Seção 2, p. 292.

6 RCrim. 9301101293-6/MG, 3 $3^{\mathrm{a}}$ T., DJU 14.06.1993, p. 22765.

7 Idem, apud "Crime contra a fauna: reflexões sobre a aspereza do código de caça". Revista dos Tribunais, v. 706, p. 427, agosto de 1999. 
proíbe o afiançamento de quem infringe o art. 129 do CP. ..".

Tribunal de Justiça do Estado de Mato Grosso já se encontra sensível ao tema da proporcionalidade em matéria ambiental, principalmente em relação a alguns dispositivos da Lei Estadual de Pesca n 7.155/99.

Nesta lei, está prevista a apreensão dos apetrechos de pesca como forma de coibir o pagamento de eventual multa para somente depois se proceder à liberação do material oriundo da infração. Aqui o princípio da proporcionalidade se fundamenta pela observância ao princípio do devido processo legal.

Destacamos alguns julgados que comprovam a atenção conferida pelos magistrados, tais como:

"MANDADO DE SEGURAN. ÇA - REEXAME NECESSÁRIO DE SENTENÇA - PESCA PREDATÓRIA - APREENSÃO DO VEÍCULO
TRANSPORTADOR-MEDIDA PREVISTA EM LEI - ILEGALIDADE SENTENÇA RATIFICADA

Revela-se inconstitucional diploma estadual, que sob o color de regulamentar lei federal, prescreve norma a fulminar garantia ínsita na Constituição da República." (Reexame Necessário de Sentença no 826 - Capital - 1 ${ }^{a}$ C.Cív. Rel. Dr. ALBERTO FERREIRA DE SOUZA - J. 30.10.1995). ${ }^{9}$

Com estes julgados, pode-se constatar a importante missão que princípio da proporcionalidade exerce sobre o direito ambiental: a de concretizar os valores de justiça, igualdade e eqüidade. Este princípio é importante para auxiliar na superação da crise pela qual passa o direito contemporâneo, onde os juízes ainda são guiados pelo espírito da lei, esquecendo-se de sua função criadora, derivada de dois fatores: a) são sujeitos imersos na sociedade $;^{10}$ b) são sujeitos que dependem do cri-

8 Op. cit., p. 428.

9 No mesmo sentido: "MANDADO DE SEGURANÇA - FRIGOMAT: FRIGORÍFICO MATO GROSSO LTDA. - TRANSPORTE DE PESCADO - APREENSÃO DO CAMINHÃO CONDUTOR - SEGURANÇA CONCEDIDA PARA A LIBERAÇÃO DO VEÍCULO REEXAME COMPULSÓRIO - SENTENÇA CONFIRMADA SEM DISCREPÂNCIA DE VOTOS. É inadmissível a apreensão do veículo como meio coercitivo para assegurar o pagamento de tributo." (Reexame Necessário de Sentença n 285 - Capital - Rel. Des. LICÍNIO CARPINELLI STEFANI - DJMT 05.08.1991, p. 02). "MANDADO DE SEGURANÇA-REEXAME NECESSÁRIO DE SENTENÇA - PESCA PREDATÓRIA - APREENSÃO DO VEÍCULO TRANSPORTADOR - MEDIDA NÃO PREVISTA EM LEI ILEGALIDADE - SENTENÇARATIFICADA. Revela-se inconstitucional diploma normativo estadual, que sob color de regulamentar lei federal, prescreve norma a fulminar garantia ínsita na Constituição da República." (Reexame Necessário de Sentença no 826 - Capital - 1aㅡ C.Cív. - Rel. Dr. ALBERTO FERREIRA DE SOUZA). Conferir site do Tribunal de Justiça de Mato Grosso: www.t.mt.gov.br

10 (E não estão fora dela!). Na visão de LÊNIO LUIZ STRECK, a crise do direito no Brasil deriva da posição cômoda dos jú́zes, que ainda se encontram interpretando a lei de acordo com a filosofia da consciência (em que se consideram na posição sujeitoobjeto, de cunho metafísico) e não da filosofia da linguagem (onde se é enfatizada a função criativa do juiz, sujeito imerso na sociedade, e não fora dela, como pregava a posição dos teóricos da filosofia da consciência). Assim, esta nova hermenêutica rompe com a idéia de subsunção do caso sobre uma regra imediata que the corresponda, partindo para a possibilidade da autonomia do texto, sendo aí relevante a aplicação do princípio da proporcionalidade. Para alcançar o desiderato de realização dos direitos, é preciso superar a concepção de que somente o paradigma normativista é o justo, e entender que além do campo individual, existe um campo jurídico, constituído por um conjunto de todos os personagens que o integram, interpretam e aplicam a lei. Passa-se da essência à significaçãa, onde o importante é saber o que dizemos quando falamos das coisas, e não saber da essência das coisas em si mesmas. In Hermenêutica jurídica em crise. Uma exploração hermenêutica da construção do direito. 3. ed. revista. Porto Alegre: Livraria do Advogado, 2001, p. 33-39, p. 69-79. 
tério ético-material para sobreviver, e por isso, são responsáveis pelo processo de mediação da factibilidade à reprodução da vida humana, um dos passos essenciais à descrição indicativa dos fundamentos da ética da libertação. ${ }^{11}$

\section{Considerações finais}

"Certo fique, outrossim, que não se pugna pela descriminalização das máculas ao meio ambiente e ao patrimônio ecológico. O desejo é tão só o da supremacia da razoabilidade no trato legal do assunto."12

$\bigcirc$ princípio da proporcionalidade, decomposto nos elementos necessidade, adequação e proporcionalidade em sentido estrito, pode ser aplicado em qualquer ordenamento jurídico, revelando-se como um imperativo a ser observado pelos operadores das leis.

No caso das normas ambientais, principalmente naquelas onde se impõe a restrição de direitos fundamentais em prol da conservação da natureza, sua observância se faz com maior peculiaridade, pois os interesses, ao mesmo tempo em que são colidentes, se apresentam mutuamente dependentes, já que em nossa Constituição, a proteção do ambiente é realizada em prol da manutenção da vida humana presente e das futuras gerações (art. 225, caput, CRB).
Observa-se que diante das dificuldades aqui apresentadas, e que giram em torno de problemas de colisão de bens e interesses, já não se mostra suficiente o caso concreto como referencial absoluto e exclusivo para a decisão. A decisão precisa ser ordenada. E devem existir critérios para isso, já que tudo não se pode resumir apenas em função dos valores, mas dos objetivos.

À afirmação não importa desconsiderar a importância dos dados e fatos para o processo de formação e elaboração da decisão, mas indica que quando se propõe a elaboração de uma fórmula procedimental, não se tem por referencial a elaboração de uma resposta absoluta e principalmente estável. Afirma-se que não se pode aceitar que a decisão possua tão elevada carga de instabilidade e volubilidade, que somente seja possível a partir do caso concreto, conduzindo a uma inaceitável perversão ou corrupção da própria pretensão de construção de uma racionalidade jurídica, em nome do retorno de uma irresponsável leitura do modelo de jurisprudência sociológica.

Quando foi proposta a aproximação do princípio da proporcionalidade - que traz em seu conteúdo os elementos da necessidade, adequação, e proporcionalidade em sentido estrito - ao Direito Ambiental, já se indica que não apenas o caso concreto deve

11 Para ENRIQUE DUSSEL, esta eticidade derivada do critério material "se constrói processual e diacronicamente, a partir da fundamentação ou decisão eletiva da norma, até a realização factível ética do ato, da instituição, das estruturas sistêmicas histórico-culturais etc., passando desta maneira da aprioridade da norma ou máxima na intenção do agente à realização da eticidade". In DUSSEL, Enrique. Ética da Libertação - na idade da globalização e da exclusão. Tradução de Ephraim F. Alves, Jaime A. Clasen e Lúcia M. E. Orth, Petrópolis: Vozes, 2000, p. 238.

12 CARVALHO, Ivan Lira. "Crime contra a fauna: reflexões sobre a aspereza do código de caça". Revista dos Tribunais, volume 706, páginas 427 a 460, agosto de 1999, p. 430. 
ser considerado como único e absoluto referencial para a formulação da decisão: é preciso reconhecer a existência de possibilidades e condições de um controle objetivo da atuação do operador do Direito em sua relação com o ambiente.

Os exemplos deste trabalho ilustram um diagnóstico positivo (e esperançoso) da comunidade jurídica no que tange à aceitação da proporcionalidade como elemento de controle da restrição tomando como parâmetro de controle o suporte material da lei conformando o texto com os objetivos a serem atuados.

$\bigcirc$ princípio da proporcionalidade não vem anular o princípio da legalidade, mas vem fortalecê-lo, amenizando a generalidade fria da lei, que por mais justa que pareça ser, é insuficiente para regulamentar e prever, no caso concreto, todos os arbítrios contra às liberdades individuais e coletivas. Ao mesmo tempo, sua aplicação desenvolve a capacidade dos juízes de re- fletir sobre o papel que exercem na realidade social: não mais simples expectadores, sempre à espera de uma lei regulamentadora, mas juízes preocupados em construir a justiça no (e do) caso concreto.

\section{Referências bibliográficas}

BONAVIDES, Paulo. Curso de direito constitucional. 4. ed. São Paulo: Malheiros, 1993.

CANOTILHO, José Joaquim Gomes. Direito constitucional. 4. ed. 2. reimpressão. Coimbra. 1992

CARVALHO, Ivan Lira. "Crime contra a fauna: reflexões sobre a aspereza do código de caça". Revista dos Tribunais, v. 706. Agosto de 1999.

DUSSEL, Enrique. Ética da libertação - na idade da globalização e da exclusão. Tradução de Ephraim F. Alves, Jaime A. Clasen e Lúcia M. E. Orth. Petrópolis: Vozes, 2000, p. 238.

STRECK, Lênio Luís. Hermenêutica jurídica em crise. Uma exploração hermenêutica da construção do direito. 3. ed. Porto Alegre: Livraria do Advogado, 2001.

STUMM, Raquel Denize. O princípio da proporcionalidade no direito constitucional brasileiro. 1. ed. Porto Alegre: Livraria do Advogado, 1998. 